East African Medical Journal Vol. 87 No. 3 March 2010

PERCEPTIONS AND VIEWS OF REGULATORY PHARMACISTS ON THE REGISTRATION SYSTEM FOR GENERIC DRUGS FOR HUMAN USE IN KENYA

A. K. Chemwolo, BPharm, MSc, School of Pharmacy, University of Bradford, Bradford, West Yorkshire, BD7 1DP, UK and Pharmacy and Poisons Board, P.O. Box 27663-00506, Nairobi, Kenya, J. Ngondi, MBChB, MPhil, PhD, DFPH, Department of Public Health and Primary Care, University of Cambridge, Robinson way, Cambridge CB2 0SR, UK and B. J. Clark, MSc, PhD, FRSC, CChem, School of Pharmacy, University of Bradford, Bradford, West Yorkshire, BD7 1DP, UK

Request for reprints to: Dr. A. Chemwolo, P.O. Box 27663-00506 , Nairobi, Kenya

\title{
PERCEPTIONS AND VIEWS OF REGULATORY PHARMACISTS ON THE REGISTRATION SYSTEM FOR GENERIC DRUGS FOR HUMAN USE IN KENYA
}

\author{
A. K. CHEMWOLO, J. NGONDI and B. CLARK
}

\begin{abstract}
Background: Generic drugs play an important role in the delivery of healthcare services in Kenya because of their affordability and availability. The Pharmacy and Poisons Board (PPB) is the body mandated to regulate the manufacture and supply of all drugs in Kenya. Approximately $\mathbf{9 0} \%$ of all applications for registration of drugs in Kenya are for generic drugs; however, there are concerns about the quality of generic drugs supplied to patients in Kenya.

Objective: The study aimed to investigate the perceptions and views of the regulatory pharmacists on the registration system for generic drugs in Kenya, and the role of the National Quality Control Laboratory (NQCL).

Design: A cross-sectional survey was designed to collect the views and perceptions of regulatory pharmacists on the system for the registration of generic drugs for human use in Kenya.

Setting: The survey was conducted in the capital city of Kenya, Nairobi from January to February 2007. Nairobi was selected because it has a high concentration of pharmaceutical manufacturers and distributors involved in drug registration.

Participants: The sample included regulatory pharmacists working in the registration departments of pharmaceutical companies dealing in generic drugs for human use. A sample of 40 participants was recruited for the survey and a response rate of $60 \%$ was targeted.

Results: Over half $(55.6 \%)$ of the respondents reported satisfaction with the drug registration system while $33.3 \%$ were unsatisfied. The level of satisfaction did not seem to be associated with the length of time it takes to register a generic drug $(p-v a l u e=0.74)$ or the gender of the respondent ( $p$-value $=0.94$ ). The respondents had confidence in the analytical procedures carried out by NQCL but were less satisfied with its role in generic drug registration process. The respondents made a number of recommendations towards better drug registration mechanisms for generic drugs in Kenya.

Conclusion: The study suggests that although the drug registration procedures appear to be working, there is need for improvement. One area in which the registration of generic drugs in Kenya can benefit is in the observation of the operation of what other countries have done to streamline their drug registration systems.
\end{abstract}

\section{INTRODUCTION}

Medicines have played a critical role in the management of various diseases and ailments for some considerable time. It becameclear that there was a need to regulate these medicines to verify the claims made on their quality, safety and effectiveness. It has been suggested that the history of drug regulation dates back to $120 \mathrm{BC}(1)$. Over theyears many societies were set up and developed pharmacopoeias and described lists of drugs, their preparation, uses and control of drug quality. It is thought that the earliest pharmacopoeia was the New compound Dispensatory of 1498 issued by the Florentine guild of physicians and pharmacists. The first London Pharmacopoeia was published in 1618 (2).

The process of regulation was accelerated later after the occurrence of disasters which resulted from patients using drugs of poor quality, with harmful ingredients and / or whichlacked in efficacy. Presently, 
the World Health Organisation (WHO) estimates that between $10 \%$ and $30 \%$ of medicines on sale in developing countries are counterfeit (3). For the most part, patients are ignorant about the risks associated with use of medicines. Hence there is need for strong regulatory bodies to assess and control the quality of drugs dispensed to the public.

Many countries have found the use of a drug registration system is appropriate as a vetting mechanism for drugs licensing. Through this, the quality, safety and efficacy of a drug are assessed and a decision made on whether it should be registered for use. The need for this regulation becomes even more urgent because of the increasing number of drugs available, the globalization of the pharmaceutical industry and the threat posed by the circulation of substandard, harmful and counterfeit drugs.

However, it is only in the last two decades that the generic drug industry has experienced tremendous growth. This suggests that knowledge in this area is often lacking and many countries are still working out the best ways of regulating generic drugs. An examination of the literature reveals that few studies have been conducted on the registration of generic drugs and the ones that are available deal with specific elements of the drug registration process. In the period 1998-1999, the WHO conducted a multi-country study involving 10 countries to assess their drug regulatory mechanisms which included an assessment of the drug registration system (4). These studies however did not involve Kenya.

One of the areas of concern in the registration of generic drugs in Kenya is the occurrence of frequent backlogs. From the early 1990s, Kenya received many applications especially for human generic drugs and there was a very large backlog of 12 months by thelate 1990s. This led to many complaints about delays from applicants. Another challenge that the PPB has faced are concerns about the openness of communication with clients and provision of adequate guidance information for applications. Other issues included the kind of additional information requested during the evaluation process and the quality of decisions made.

Perhaps the most critical challenge is concern about the quality of generic drugs in the marketplace. This has negatively impacted on the promotion of generic prescribing and generic substitution. There are also questions regarding the presence of too many generic brands per active ingredient in the market. Hence it is suggested that there is a need to assess whether the evaluation of generic drug applications by the PPB is optimal.

During the course of its work in assessing the quality of generic drugs, PPB may decide to recommend samples for analysis. Samples are usually sent to the NQCL which is a government laboratory setup in 1992 through an amendment to the Pharmacy and Poisons Act, Chapter 244 (5). The laboratory on behalf of the government carries out tests requested by PPB on drug products and medicinal substances to determine whether they comply with their quality specifications. However, delays have occurred at this stage due to the laboratory taking long to release certificates of analysis. There have also been questions about the criteria used to decide which drug products to analyse.

There are still a number of gaps to be filled in the understanding of the registration system for generic drugs in Kenya. Approximately $90 \%$ of all applications for registration of drugs in Kenya are for generic drugs hence their quality, safety and efficacy has profound effects on the healthcare system. This study was therefore conducted to identify the gaps in the registration of generic drugs in Kenya and suggest ways of improving it.

\section{MATERIALS AND METHODS}

Study design and setting: A cross-sectional survey was designed to collect the views and perceptions of regulatory pharmacists on the system for the registration of generic drugs for human use in Kenya. The survey was conducted in Nairobi, the capital city of Kenya. Nairobi city was chosen because it has a high concentration of pharmaceutical manufacturers and distributors involved in drug registration.

Population, sample size and sampling: The population was composed of the agents of foreign-based and local pharmaceutical manufacturers based in Nairobi which register drugs for human use with the PPB. The list held by the Drug Registration Department of the PPB was used to find the population frame. On applying the inclusion and exclusion criteria to the population frame the study recruited a sample of 40 participants and the whole sample was selected to participate in the survey. A response rate of at least $60 \%$ was targeted. The regulatory pharmacist employed by each of these companies was recruited for the survey. A regulatory pharmacist was considered as one who worked for a pharmaceutical company and was involved in the registration of drugs.

Survey questionnaire: The survey questionnaire was developed in English and comprised of questions on various aspects of generic drug registration in Kenya and the role of NQCL. The questionnaire was distributed to the participants and completed by selfadministration. Follow-up was conducted to ensure the completed questionnaires were returned. 
Data analysis: The survey data was cleaned and edited for errors before being entered and analysed using SPSS 12.0 software. Descriptive statistics were used to summarise the respondents' characteristics and the key results. Associations between variables were assessed using Pearson's Chi-square test and a p-value of less than 0.05 was considered to be statistically significant.

Ethical considerations: Before carrying out the survey, permission was obtained from the registrar of the PPB to access records and recruit participants. For this study, informed consent was assumed to have been obtained when a participant agreed to voluntarily fill and return the questionnaire. All data collected was anonymous.

\section{RESULTS}

Characteristic of the respondents: Table 1 summarises the characteristics of the respondents. A total of 40 participants were recruited for the survey of whom 31 returned completed questionnaires (a response rate of $77.5 \%$ ). However on checking the acceptance criteria and background, only 27 respondents met the inclusion criteria and were included in the data analysis. The non-responders did not have any significant difference from the responders and therefore are not expected to affect the results. Majority of the respondents $(68 \%)$ fell within the age range 31 to 40 years. The number of years of experience in drug registration ranged from 1 year to 30 years with a mean of 9.3 years and a median of 7 years.

Table 1

Distribution of respondents by age and gender*

\begin{tabular}{|c|c|c|c|c|}
\hline \multirow{2}{*}{$\begin{array}{l}\text { Age group (years) } \\
\text { Below } 30\end{array}$} & $\begin{array}{c}\text { Males } \\
\text { No. }(\%)\end{array}$ & $\begin{array}{l}\text { Females } \\
\text { No. }(\%)\end{array}$ & \multicolumn{2}{|c|}{$\begin{array}{c}\text { Total } \\
\text { No. }(\%)\end{array}$} \\
\hline & & $\begin{array}{ll}3 & 12\end{array}$ & 3 & 12 \\
\hline $31-40$ & $7 \quad 28$ & $4 \quad 16$ & 11 & 44 \\
\hline $41-50$ & $6 \quad 24$ & & 6 & 24 \\
\hline Over 50 & $5 \quad 20$ & & 5 & 20 \\
\hline Total & $\begin{array}{ll}18 & 72\end{array}$ & $\begin{array}{ll}7 & 28\end{array}$ & 25 & 100 \\
\hline
\end{tabular}

*one person missing age and gender and one person missing gender only were excluded

Perceptions of respondents on the introduction of new policies and procedures: The views of the respondents on the development of various policies and procedures for generic drug registration are summarised in
Table 2. Except for theintroduction of annual retention fee procedure $(30.8 \%)$, over half of the respondents supported the introduction of the various policies and procedures at PPB (range, 53.8\% to 100\%).

Table 2

Views on introduction of policies and procedures at PPB

Policies and procedures
Support for introduction of policies \& procedures Yes No

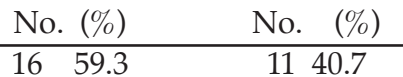

Introduction of a policy to limit number of generic drugs per active ingredient Introduction of annual retention fee per product

$\begin{array}{llll}8 & 30.8 & 18 & 69.2\end{array}$

GMP inspection of manufacturing facility prior to registration of drugs

Use of internal evaluators by the PPB

Introduction of timeframe for evaluation of applications by the PPB

Introduction of timeframe for responding to queries by applicants

Introduction of electronic submission of applications

Development of web site for tracking status of applications by applicants Introduction of a policy on which classes of generics should be analysed

$23 \quad 85.2$

$4 \quad 14.8$

1970.4

$8 \quad 29.6$

$27 \quad 100$

$23 \quad 85.2$

$23 \quad 85.2$

$4 \quad 14.8$

$25 \quad 96.2$

$4 \quad 14.8$

$14 \quad 53.8$

13.8

1246.2

Introduction of a policy on which generic drugs to undergo bioequivalence testing 1976.0 
Level of satisfaction with certain policies and procedures: Table 3 summarises the level of satisfaction of respondents with drug registration procedures and vaccines should be more stringent than those of other generic drugs compared to three (11.5\%) who thought they should be the same. The majority of the

Table 3

Responses to questions on policies and procedures of drug registration

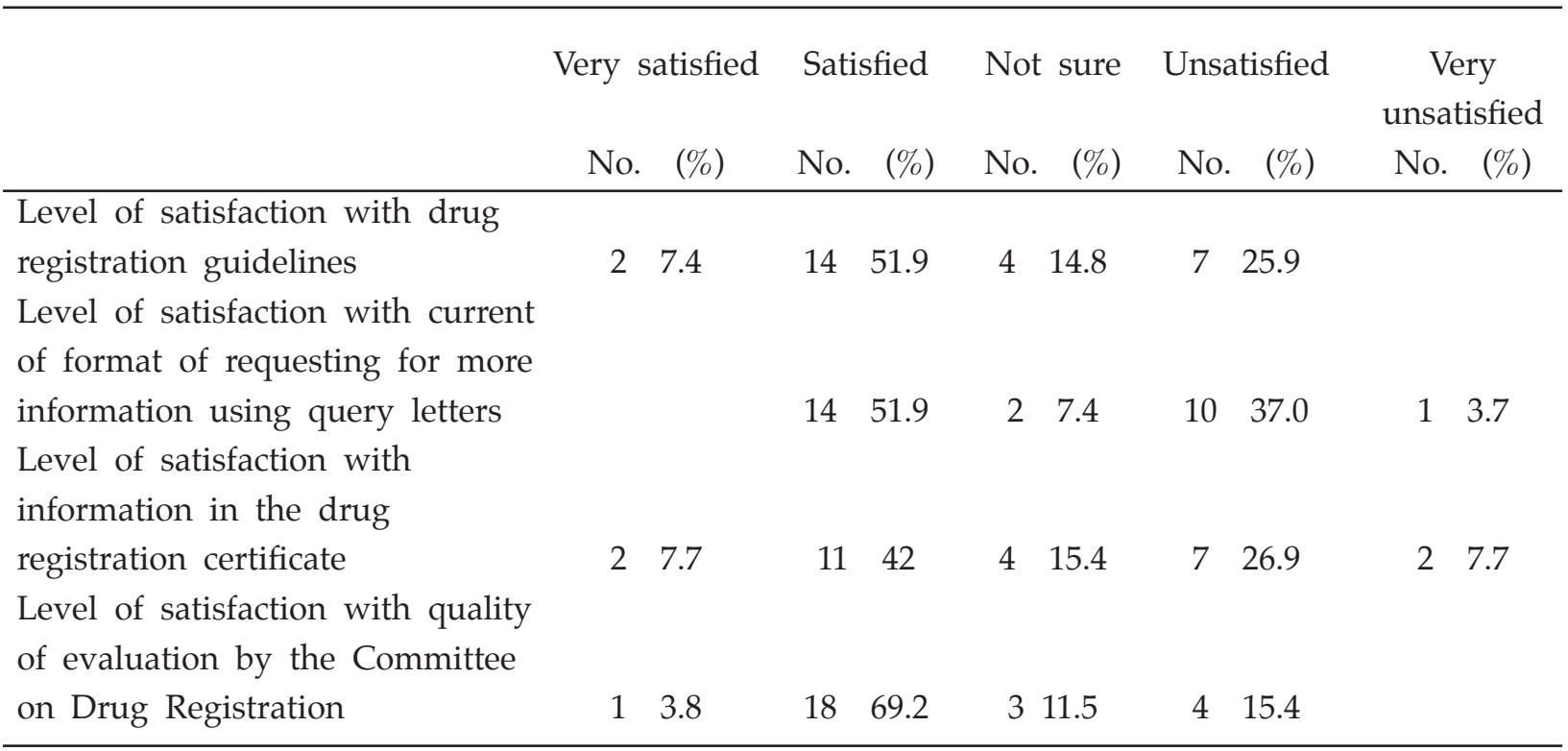

documents. For all questions asked, more than half of the respondents reported that they were satisfied or very satisfied.

Responses on registration requirements for generic drugs and biological products: Sixteen $(59.3 \%)$ of the respondents suggested that the registration requirements for a generic drug should be made less stringent than those for a new drug compared to 11 $(40.7 \%)$ who thought the requirements should be the same. On the other hand, a significant proportion of the respondents $23(88.5 \%)$ felt that the registration requirements of generic biological products and respondents were of the view that the harmonisation of drug registration requirements in East Africa was long overdue and needed to be speeded up.

Responses to questions on the content of the application: Table 4 summarises the responses to questions regarding the content of the application. Respondents reported high levels of satisfaction (satisfied or very satisfied) with administrative sections $(92.6 \%)$ and pharmaceuticalsections $(77.8 \%$ ) of the drug registration dossier. However, there was less satisfaction with the clinical sections of the registration dossier (reported satisfied or very satisfied $=48.1 \%$ ).

Table 4

Responses to questions on the level of satisfaction with the format of the drug registration dossier

\begin{tabular}{|c|c|c|c|c|c|c|}
\hline & $\begin{array}{r}\text { Very } \\
\mathrm{N}\end{array}$ & $\begin{array}{l}\text { satisfied } \\
\text { o. }(\%)\end{array}$ & $\begin{array}{l}\text { Satisfied } \\
\text { No. }(\%)\end{array}$ & $\begin{array}{l}\text { Not sure } \\
\text { No. }(\%)\end{array}$ & $\begin{array}{c}\text { Unsatisfied } \\
\text { No. }(\%)\end{array}$ & Very unsatisfied \\
\hline administrative sections (1-7) & 8 & 29.6 & $17 \quad 63$ & 13.7 & 13.7 & \\
\hline $\begin{array}{l}\text { Level of satisfaction with } \\
\text { pharmaceutical sections (8-16) }\end{array}$ & 5) 3 & 11.1 & $18 \quad 66.7$ & & $\begin{array}{ll}6 & 22.2\end{array}$ & \\
\hline $\begin{array}{l}\text { Level of satisfaction with } \\
\text { clinical sections }(17-19)\end{array}$ & 2 & 7.4 & 1140.7 & 13.7 & $\begin{array}{ll}9 & 33.3\end{array}$ & $\begin{array}{ll}4 & 14.8\end{array}$ \\
\hline
\end{tabular}


The role of the National Quality Control Laboratory: The PPB often selects samples for analysis in the laboratory before registration. In the responses to a question on relevance of this pre-registration analysis, $18(66.7 \%)$ of the respondents thought it was very relevant, five $(18.5 \%)$ thought it was relevant, three $(11.1 \%)$ were not sure and one $(3.7 \%)$ thought it was irrelevant. The responses to the question on the method of analysis which thelaboratory should use in analysing samples were varied and $12(52.2 \%)$ of the respondents felt that the laboratory should use the method and specifications stated in the official pharmacopoeias, seven $(30.4 \%)$ thought the laboratory should use the same method and specifications used by the manufacturer, three $(13 \%)$ thought the laboratory should use the method that it has adopted, and one $(4.3 \%)$ felt that the laboratory should use the method and specifications of theinnovator company. The data is shown in Table 5 which summarises the responses on who should provide reference standards to be used in the analysis and who should pick sample for analysis. drug registration process was divided and a large proportion of the respondents seemed to be unsure. Those who were unsatisfied felt that the laboratory should play a greater role in post-market surveillance of drugs.

A similar scenario was repeated in their perceptions of the length of time it takes to analyse a drug at the NQCL whereas six $(23.1 \%)$ of the respondents thought that it was satisfactory, nine $(34.6 \%)$ were unsure, seven $(26.9 \%)$ thought it was unsatisfactory while four $(15.4 \%)$ thought it was very unsatisfactory.

Satisfaction with the drug registration system: More than half of the respondents were satisfied with the current system of drug registration in Kenya whereby one $(3.7 \%)$ were very satisfied, $14(51.9 \%)$ were satisfied, two $(7.4 \%)$ were unsure and nine $(33.3 \%)$ were unsatisfied. On the perception of the length of time it takes to register a generic drug in Kenya, five (18.5\%) felt it was too long, 14(51.9\%) felt that it was long, seven (25.9\%) thought it was acceptable while one $(3.7 \%)$ thought it was short. From these data, it appears that most of the

Table 5

Responses on questions on who should submit reference standards and pick of analytical samples

\begin{tabular}{lcccc}
\hline & $\begin{array}{c}\text { Provision of reference standards to } \\
\text { NQCL for analysis }\end{array}$ & \multicolumn{2}{c}{$\begin{array}{c}\text { Opinion on who should } \\
\text { pick samples for analysis }\end{array}$} \\
\hline No. & $(\%)$ & No. & $(\%)$ \\
PPB & 4 & 16.0 & 6 & 25.0 \\
Laboratory & 8 & 32.0 & 9 & 37.5 \\
\hline
\end{tabular}

The majority of the respondents had confidence in the validity and reliability of the analytical results of the NQCL in which four $(14.8 \%)$ said they were very confident, 14 (51.9\%) were confident, eight (29.6\%) were unsure and one $(3.7 \%)$ were not confident.

Less than half of the respondents were satisfied with the role of NQCL in generic drug registration although a significant proportion was also unsure. From the responses, $11(40.7 \%)$ were satisfied, 10 $(37.0 \%)$ were unsure, four $(14.8 \%)$ were unsatisfied while two $(7.4 \%)$ were very unsatisfied. Hence opinion on the role of the laboratory in the generic respondents were not satisfied with how long it takes to register a generic drug in Kenya.

There was no association between the level of satisfaction with the current system for the registration of generic drugs and the gender of the respondent ( $p$-value $=0.94$ ), and the level of satisfaction and the perception of respondents on length of time to register a generic drug in Kenya ( $\mathrm{p}$-value $=0.74)$. The levels of satisfaction by respondents' gender and the respondents' opinion on length of time to register a generic drug are shown on Table 6.

Table 6

Associations between level of satisfaction and the gender and perception of length of time to register a generic drug

Level of satisfaction with current system of drug registration

\begin{tabular}{llcccc} 
& & Satisfied Unsatisfied & Chi-square & P-value \\
\hline Respondents gender & Males & 10 & 7 & 0.006 & 0.94 \\
& Females & 4 & 3 & & \\
Respondents opinion on length of & & & & & \\
time to register a generic drug & Satisfactory & 5 & 3 & 0.109 & 0.74 \\
& Unsatisfactory & 10 & 8 & & \\
\hline
\end{tabular}


The rating of the level of satisfaction with the registration system for generic drugs was banded as follows: Very satisfied and Satisfied were banded together as 'Satisfied' while Not Sure, Unsatisfied and Very Unsatisfied were banded together as 'Unsatisfied'. For responses of opinion on how long it takes to register a generic drug in Kenya, Too long and Long were banded together as 'Unsatisfied' while Acceptable and Short were banded together as 'Satisfied'. This banding was done to get $2 \times 2$ table for Chi-square test computations.

\section{DISCUSSION}

This study presents important findings on the perceptions and views of the regulatory pharmacists on the registration system for generic drugs in Kenya, and the role of the National Quality Control Laboratory (NQCL). Although more than half of the respondents $15(55.6 \%)$ were satisfied with the system of registration for generic drugs in Kenya, a significant proportion was also unsatisfied (33.3\%). Most of the respondents wanted the requirements for the registration of generic drugs to be less stringent than for innovator drugs. One of the examples highlighted was the need to remove the requirement for submission of clinical studies for generic drugs. However, the majority of the respondents suggested that the registration requirements for generic biological products should be more stringent than for other generic drugs. These results therefore suggest that respondents would like a review of the information required to be included in the dossiers to meet the specific needs and circumstances of different applications.

The respondents generally supported a critical review of the drug registration system so that it is more robust, efficient, transparent and effective. The majority of respondents thought that the preregistration analysis of samples was relevant. They however seemed to be unclear as to the role of NQCLin the registration of generic drugs but were nonetheless confident about the quality of their analyses.

Many of the respondents pointed out that it is just not enough to have a good registration system. Support for the processes such as GMP inspections, post-registration surveillance and pharmacovigilance should also be in place to ensure that good quality, safe and efficacious drugs reach consumers. The respondents were concerned aboutaccountability and transparency in the drug registration processes at the PPB. They suggested among other things the setting of target timeframes for the registration process, establishing tracking systems for applications, and providing applicants with an opportunity for consultation before an application is rejected.
The respondents appear to have considered other factors apart from the length of time it takes to register a generic drug in Kenya in deciding on their level of satisfaction with the drug registration system. This may mean that there are many factors at play in the process of registration of a drug that need to be looked into to address concerns of applicants. The survey therefore succeeded in revealing the views and perceptions of the regulatory pharmacists on the registration process for generic drugs which would be useful during a review of the system.

On methodological issues the cross-sectional survey was considered appropriate for collecting information on the views and perceptions of those familiar with the drug registration system in Kenya. Only regulatory pharmacists were involved because of the technical nature of the questions and bearing in mind that the questionnaires were self-administered. The option was chosen to cut costs and save time. However, our study has a number of limitations. Firstly, the survey sample included only participants from Nairobi and therefore the results may not be generalisable nationally. A future survey could widen the range of respondents to other groups and wider geographic area which would allow more robust comparisons to be carried out. In addition, the cost implications and the impact of implementation of the recommendations made were not estimated in the study. Further research on costs is required before implementation to ensure sustainability in the long run.

This study found that the drug registration system is a critical element in the management of the drug supply in a country. Through this system, a country filters what medicines are allowed to reach its citizens. Hence ensuring the quality, safety and efficacy of generic drugs is critical to the success of the policy of the government of promoting generic procurement, prescribing and dispensing to improve access to essential medicines. Proper regulation of the registration process to provide assurance on the interchangeability of pharmaceutical equivalents should therefore be part of that strategy. Well thoughtout post-market surveillance and pharmacovigilance programmes should also be implemented. The respondents of this study found the system of generic drug registration fairly satisfactory but put forward many useful perspectives and recommendations that need further consideration.

In conclusion, the respondents generally supported a critical review of the drug registration system to make it more robust, efficient, transparent and effective. A number of recommendations can be made as a result of this work, including: 
(i) A review of the information required to be included in the dossiers submitted to meet the specific needs and circumstances of different applications would streamline the applications process.

(ii) There is need for applicants to demonstrate the quality, safety and efficacy of their products through the submission of validation data, pharmaceutical development study reports, drug master files, batch manufacturing records and biopharmaceutics study reports. This will ensure that applicants fully understand their products and have identified the critical formulation and manufacturing process parameters that impact on quality. Circumstances under which certain exemptions may be granted should be laid down in the regulations.

(iii) Post-registration surveillance of drugs needs to be strengthened so that their quality is not compromised in the market. There needs to be a mechanism for the detection and identification of unregistered, substandard and counterfeit drugs.

(iv) The role of the National Quality Control Laboratory needs to be strengthened to assist in ensuring the quality, safety and efficacy of drugs before and after registration.

(v) The PPB needs to be more transparent and accountable to the applicants. Modalities for making electronic submissions, setting up a computerised tracking system for applications and developing internal capacity of PPB to evaluate drug registration applications more rapidly should be explored. There is also need to have clear timeframes for the disposal of applications.

\section{REFERENCES}

1. Griffin, J.P. and Shah, R. R. History of drug regulation in the UK. In: The regulation of medical products (ed. J. P. Griffin and J. O'Grady). London: Brit. Med. J. Publ. Group. 2003.

2. Cartwright, A. C. Introduction and history of pharmaceutical regulation. In: Pharmaceutical Product Licensing requirements for Europe (ed. A. C. Cartwright and B. R. Matthews). New York: Ellis Horwood; 1991.

3. World Health Organization. Counterfeit medicines. Geneva: World Health Organization; [Revised 2006 November 14; Cited 2009 September 29]. Available from: http:/ / www.who.int/medicines/services / counterfeit/impact/ImpactF_S/en/index.html

4. Ratanawijitrasin, S. and Wondemagegnehu, E. Effective drug regulation: A multicountry study. Geneva: World Health Organization; 2002.

5. Government of Kenya. The Pharmacy and Poisons Act Chapter 244. Nairobi. Government Printers. 2002. 